\title{
Chalkware, Plaster, Plaster of Paris
}

\author{
Sally Promey
}

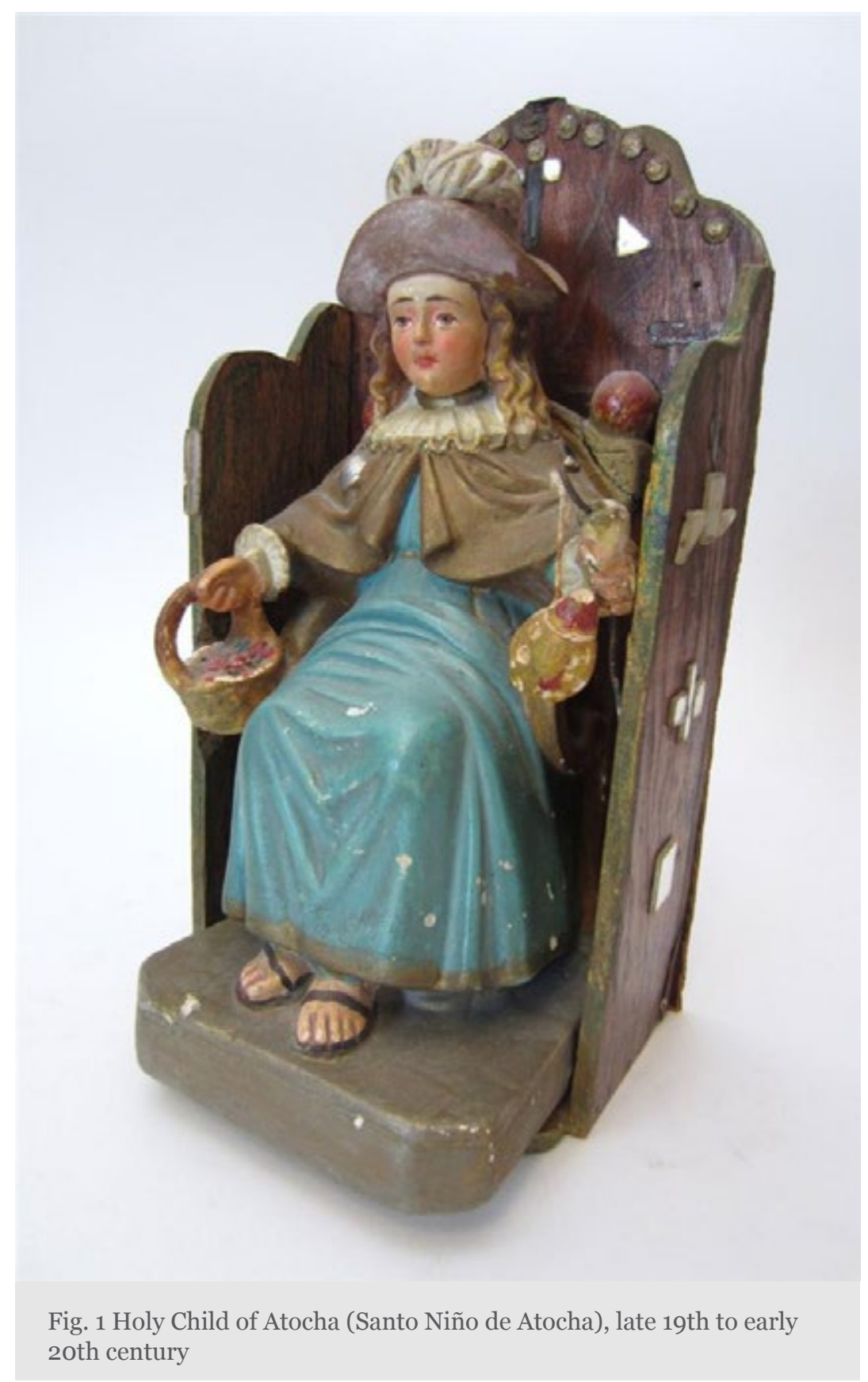

In the second half of the nineteenth century, in Europe and the United States, chalkware accomplished for three-dimensional devotional objects what chromolithography managed for images in two dimensions. ${ }^{1}$ Both of these visual and sensory technologies, furthermore, came into common usage just as European and American Christian missionary activity entered a new phase of domestic and global enterprise. These media and their suitability to emerging capital marketplaces in a period of empire building (religious and otherwise) facilitated the export and inculcation of Western Christian 


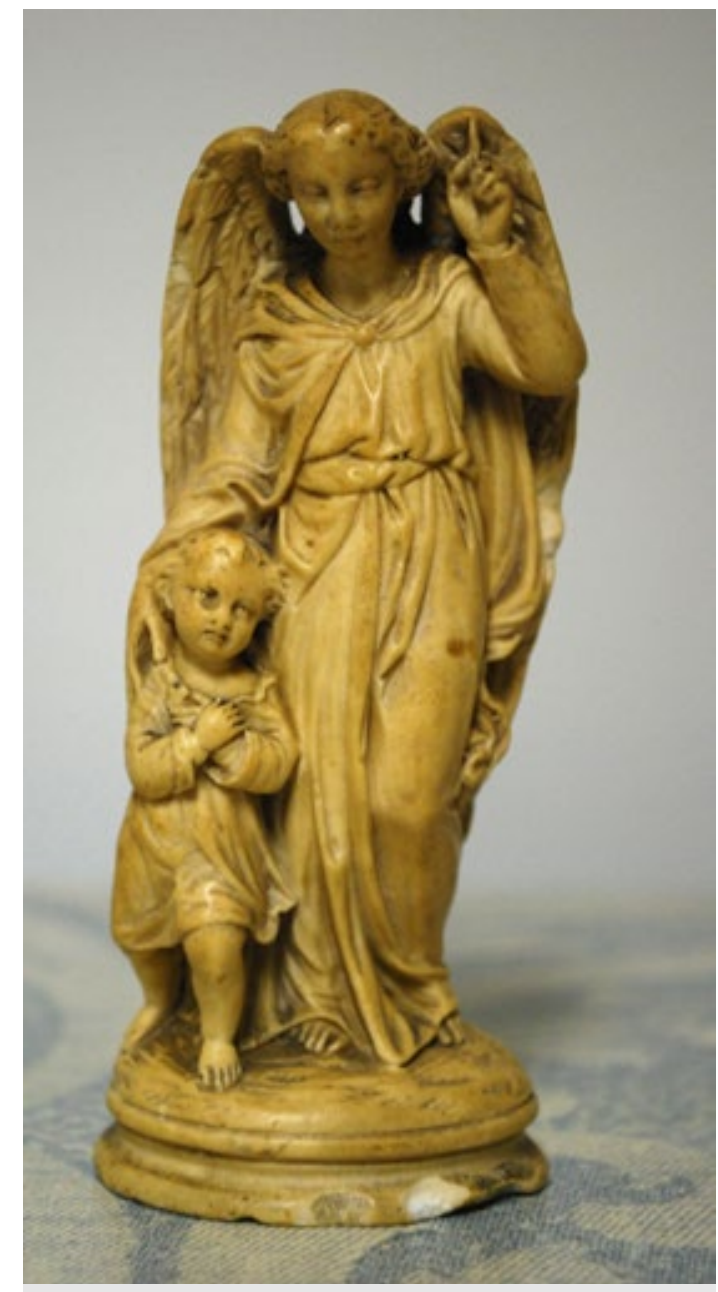

Fig. 2 Plaster Guardian Angel with Child, late 19th century

ideas, beliefs, and values. Chalkware sustained its peak popularity from the late eighteenth century through the mid-twentieth century, though it is not entirely clear when in the process it acquired this name.

This short study offers a preliminary exploration of a range of specific uses of chalkware statuary in late nineteenth- and twentieth-century Christian homes, schools, churches, and landscapes, and in various missions fields. I am interested in the material and sensory properties of this medium, and in the kinds of objects these properties facilitated.

The everyday medium of plaster has a centuries-long history in artist's workshops and sculpture studios as well as interior architectural decoration. ${ }^{2}$ Like wax, plaster maintained ritual uses as well artistic ones, generating such objects as death masks, ephemeral monuments and effigies, and religious tableaux for indoor and outdoor settings.

The production of plaster casts or other plaster wares begins with a dry, fine white 
powder, produced by heating the mineral compound gypsum. Gypsum plaster, as distinct from lime plaster (more commonly used in fresco and whitewash, for example), is also named Plaster of Paris for the large deposits of the material in Paris near Montmartre. When mixed with water, depending on the proportions, plaster powder becomes a slurry or paste-like substance that releases heat in the process of hardening. In its liquid forms, it is poured into molds to produce all manner of decorative and devotional objects. On occasion other binding agents, like glue, might be added to the liquid mixture to yield different working surfaces. Once hardened, the molds are removed and the surfaces are sanded or worked in various ways and with a range of tools, to smooth, refine, and ornament.

Plaster (by the late nineteenth-century, especially in the context of domestic and devotional objects, also called chalk or chalkware) lent itself to a higher degree of detail and specificity than wax, to greater precision in surface effects and texture, and also provided a surface well suited to paint, and thus to polychromatic images and objects (note faux wood-graining on plaster chair back of the hand painted Santo Niño de Atocha in Fig. 1). The surfaces of unpainted finished plaster could also be coated with a varnish, shiny or matte, to protect the surface or waxed to provide a smooth inviting touch, most often for smaller more intimately scaled pieces (like the small guardian angel in Fig. 2, with the waxed surface discolored by body oils from frequent handling over time).

In the nineteenth century, plaster became a primary medium for finished ecclesiastical, commercial, educational, and domestic objects, as well as for preliminary sculptural maquettes and finished casts that reproduced fine art objects for aesthetic and educational circulation in collections in museums, universities, and other schools across Europe and the United States. Plaster also assumed a genealogy that asserted relations with other fine "white" artistic media, alabaster (to one form of which it was chemically related), marble, and porcelain chief among them, but also ivory and bone. Chalkware could be produced in a wide variety of grades, depending on both the amount of hand labor expended on the surface decoration and on the materials themselves (the fineness of grain and degree of pulverization as well as the addition of other substances like ground rice, potato, or other stone or mineral "compositional" elements to the plaster dust or glue to the binder). ${ }^{3}$

Chalkware items proliferated rapidly and widely in the domestic markets of the United States and Europe, showing up in higher grades in parlors and also in less refined grades as carnival prizes (compare the 3-D version of Raphael's Madonna of the Chair in Fig. 3 with the Carnival Crucifix in Fig. 4). Objects cast from the same mold, in multiple, might be painted in very different ways, producing finished pieces with fairly dramatic variations, as these four 3-D versions of Raphael's Madonna of the Chair show (photo that includes all four of them). Especially in the first half of the twentieth century, a number of named artists, most of them women (Alice Cranston Fenner in New Preston, CT, for example, or Jo Mead in Chicago, IL) produced their own more artistically individualized chalkware objects. Fenner's Girl Praying (Fig. 5) and Jo Mead's version of the Raphael Madonna of the Chair (Fig. 6) demonstrate some possibilities. 


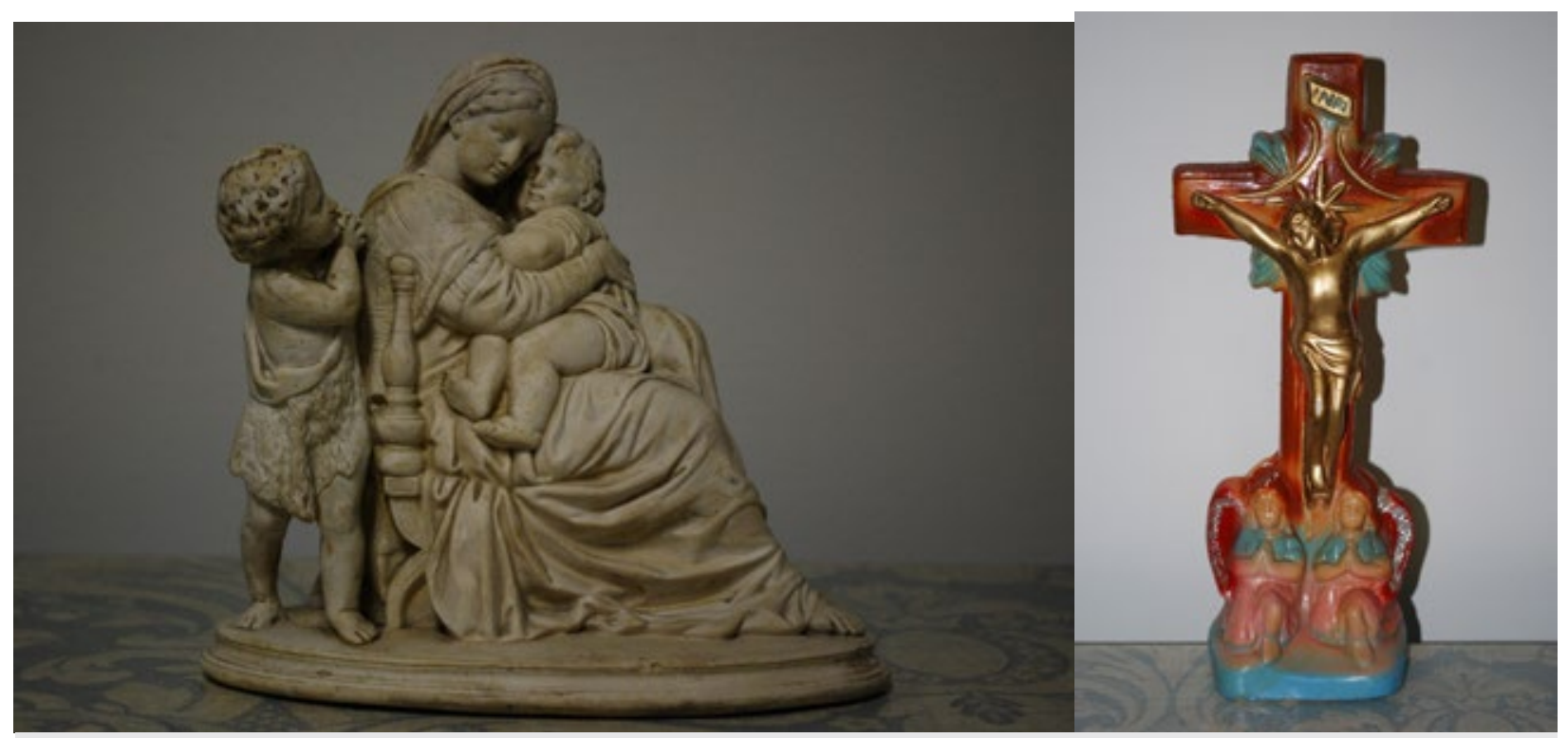

Fig. 3 Madonna of the Chair (after Raphael) - now 3D

Fig. 4 Carnival Crucifix

By the early twentieth it is fair to generalize, from supply catalogs and surviving objects, the formation of three principal sometimes overlapping subject categories: religious objects (statues and plaques); domestic decoration generally based on various arrangements of fruit, flowers, and animals; and figures or faces that purported to classify (and theorize) various gendered ethnic or national types, by skin color, facial features, and contemporary ideas about "typical" activities. This latter category of objects might be usefully compared to contemporary archaeological and anthropological uses of plaster casts for similar purposes. Representations, especially in bust form, of recognizable historical personages (religious, political, cultural, and from burgeoning entertainment industries) formed a fourth but somewhat less frequent subject category. Statues of identifiable persons as well as ethnic types were occasionally subject to caricature, sometimes extreme.

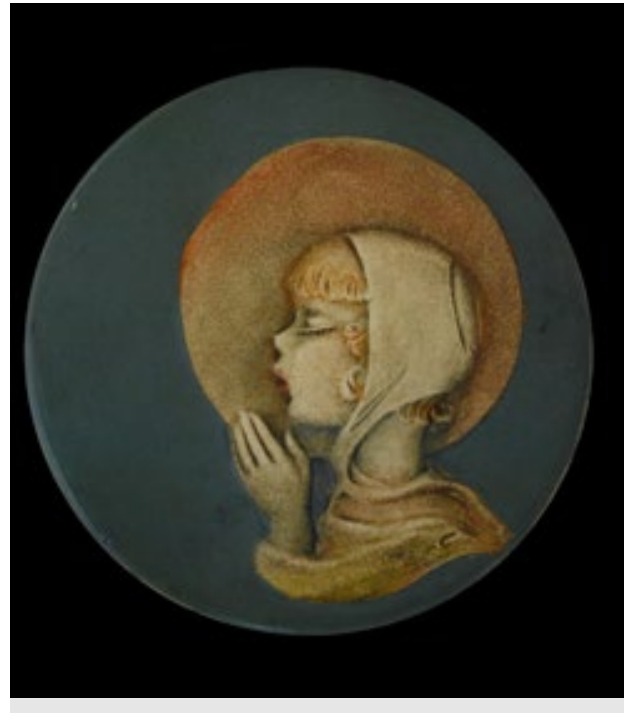

Fig. 5 Alice Cranston Fenner, Girl Praying, ca. 1942

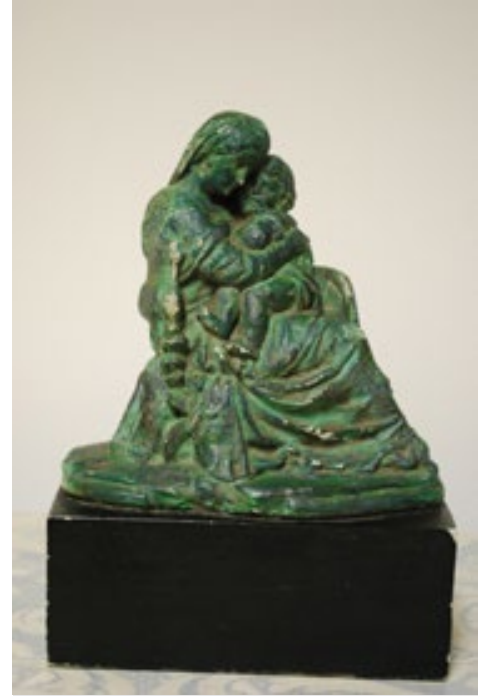

Fig. 6 Jo Mead, Madonna of the Chair (after Raphael) now $3 \mathrm{D}$ 
I offer here only a few comments on aspects of chalkware's production, use, and attraction.

First, these objects assumed mobility in multiple senses. They functioned as gifts, moving from one person to another, usually with an inscription remarking upon the special occasion of their exchange. Two examples include the carnival-ware angel in Fig. 7 with its inscription (Fig. 8) and this electrically lighted home altar (Figs 9 and 10) that was gifted in the same family twice, for Christmas in 1950 and again in 2006 as "a remembrance."

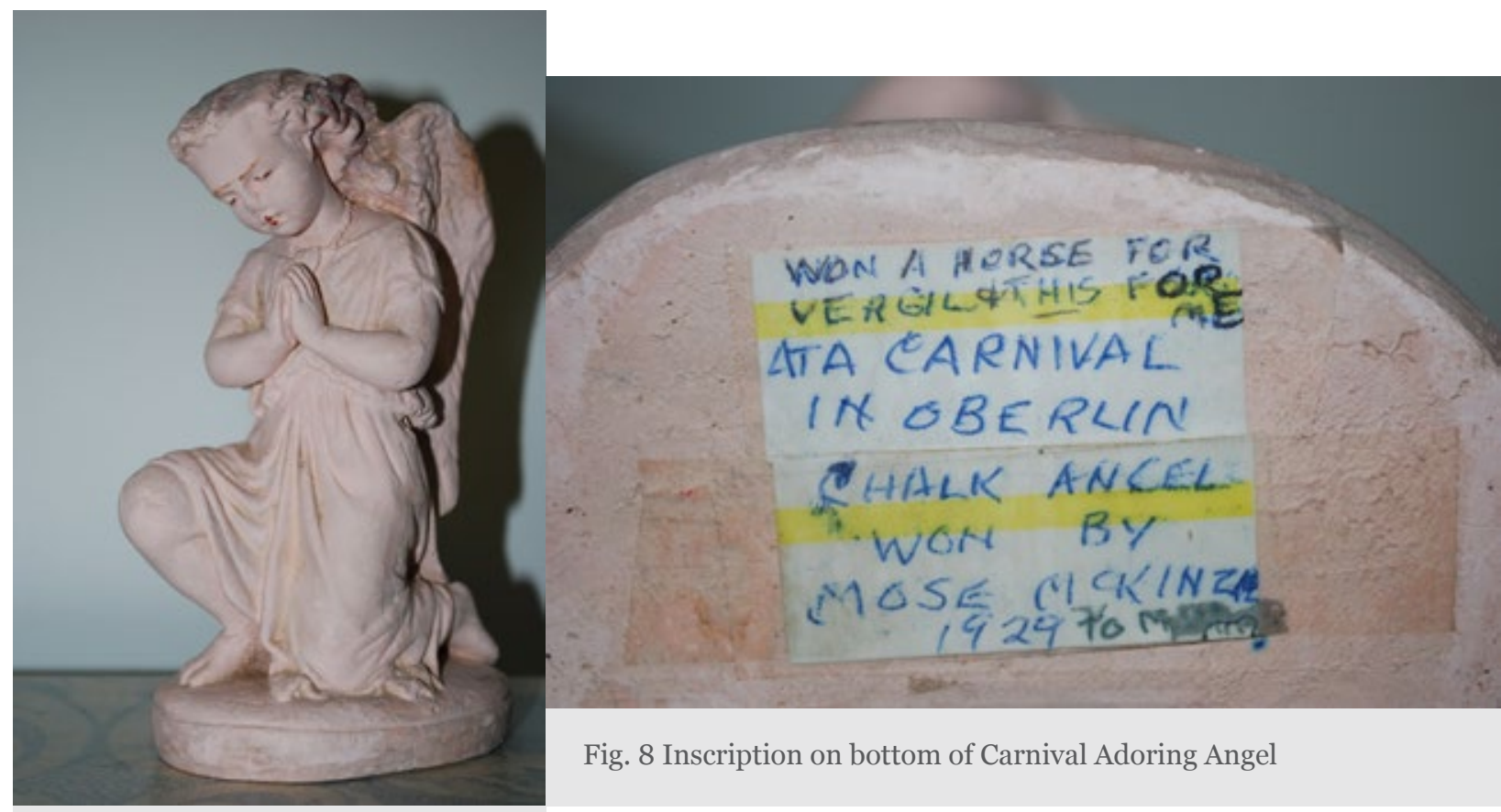

Fig. 7 Adoring Angel Carnival Prize, ca. 1929

Chalkware figures and plaques, furthermore, moved frequently into the economies of the international missions field. Occasionally the means of production moved as well with objects being reproduced by artisans among Christian converts, in China for example. Sometimes the movement of these objects seemed also to carry a kind of "antimobility" or "freezing" of the object's specific connection to some other place, elsewhere, as when plaster casts of religious figures maintained specific geographical connections to sacred sites in Europe and North America, with plaster (and concrete) statues of Our Lady of Lourdes, for example, or Saint Thérèse of Lisieux or Saint Anne de Beaupré. In these cases the message was potentially doubled back on itself: the Lourdes grotto could be anywhere (the connection to Our Lady of Lourdes could happen at its French site of origin or in China or in the Hawaiian Islands) but the French site also maintained its privilege for pilgrims and devotees and the French site maintained a sensory density sometimes lost in transport. By this I mean simply that the distinctive and exuberant uses of candles and spring water at the original Lourdes shrine seldom translated to 


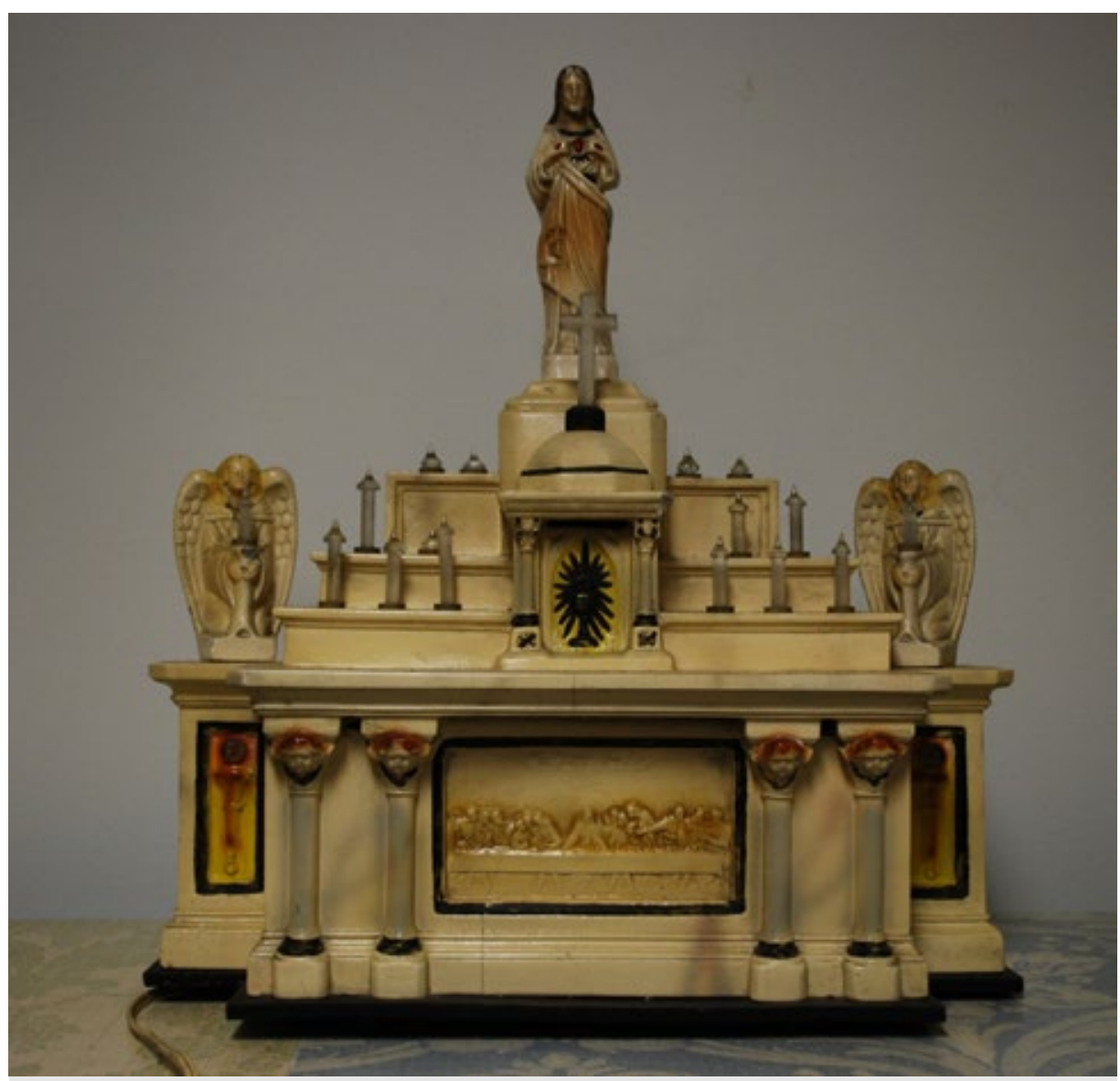

Fig. 9 Domestic Altar, ca. 1950

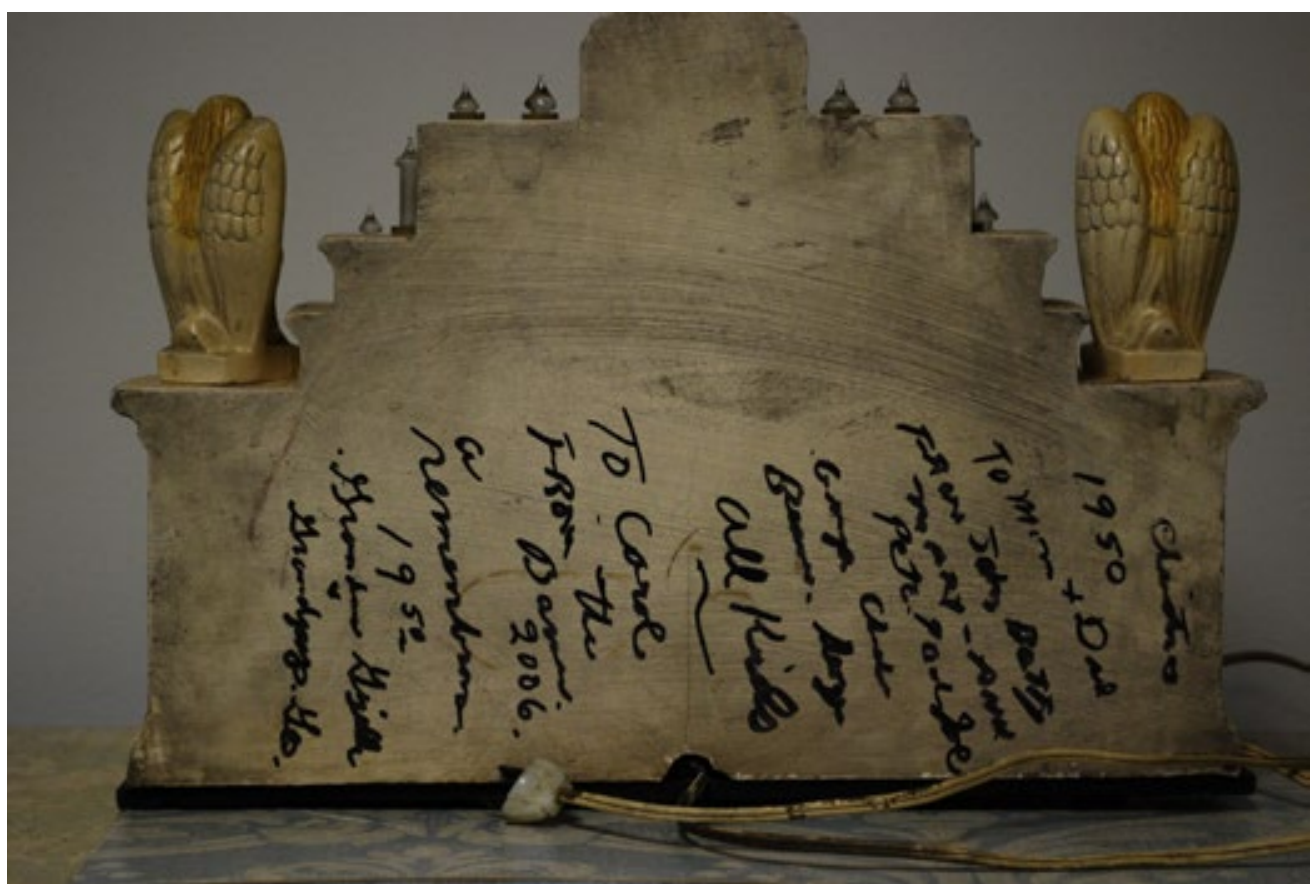

Fig. 10 Inscription on the back of the Domestic Altar 
Lourdes grottoes elsewhere which relied more heavily on the representational capacities of the natural enclosure and on statues of Our Lady of Lourdes and of the visionary Bernadette. Lourdes shrines multiplied in many scales, from four-inch chalkware versions in homes to life-scale figures in ecclesiastical chapels and outdoor shrines in locations claimed by Catholics the world over (I will write a Lourdes essay another time). In private homes too, these "places" did sometimes invite the lighting of candles and occasionally offered holy water, but not with the expansive iterative qualities of these practices at Lourdes itself.

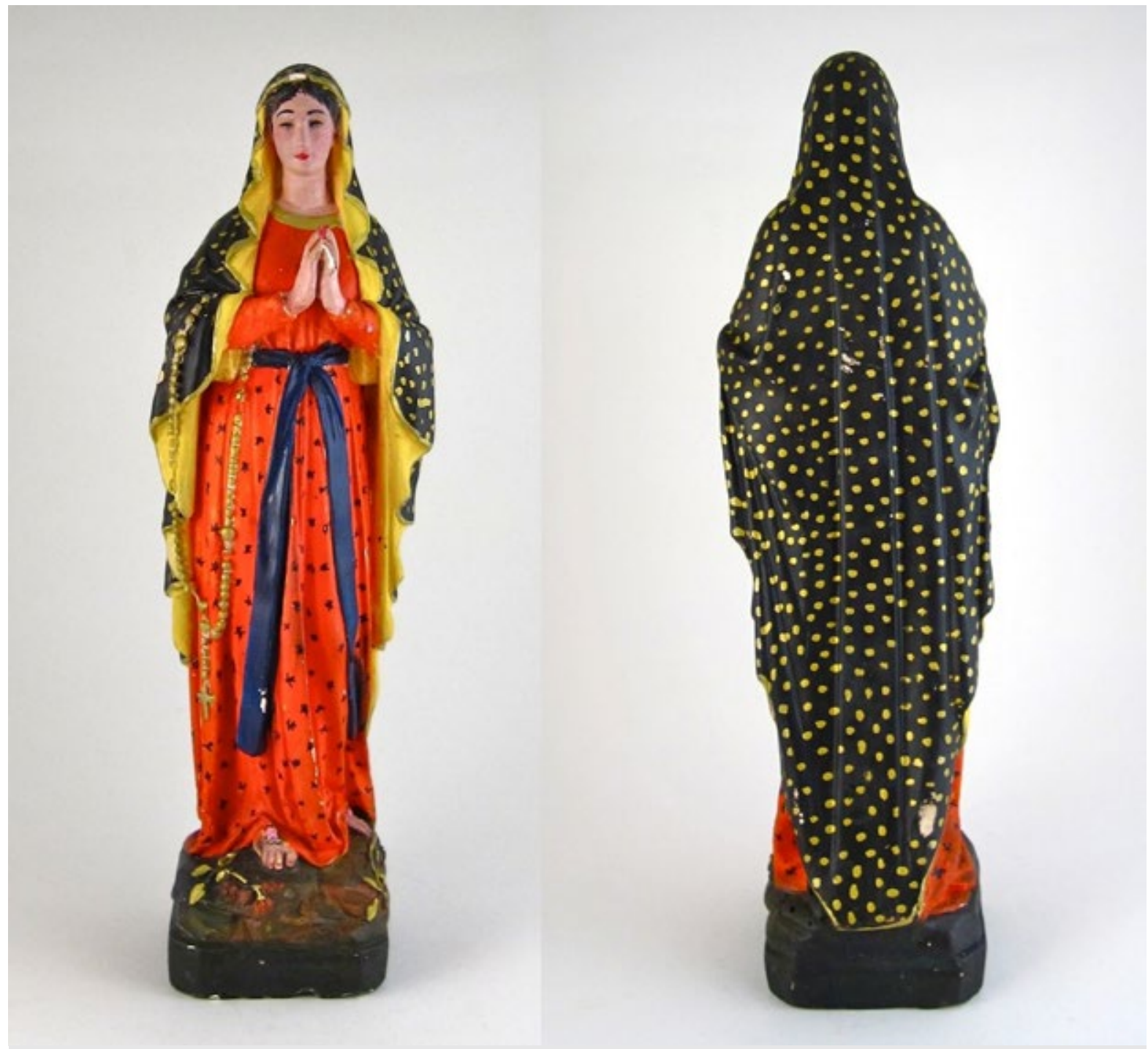

Fig. 11 Our Lady of Lourdes as the Virgin of Guadalupe, 1920s-1930s

Second, the physical care lavished upon chalkware objects is worth remarking. In some cases, claims for intricate hand-decoration or amplification seemed to refute or at least modify the impact of the object's status as mass-produced plaster cast. Two examples include a Santo Niño de Atocha with its own handmade wooden throne (See Fig. 1) and a figure that began its devotional life as Our Lady of Lourdes but was repainted as the Virgin of Guadalupe (Fig. 11). Devotees, furthermore, dressed and decorated the figures 


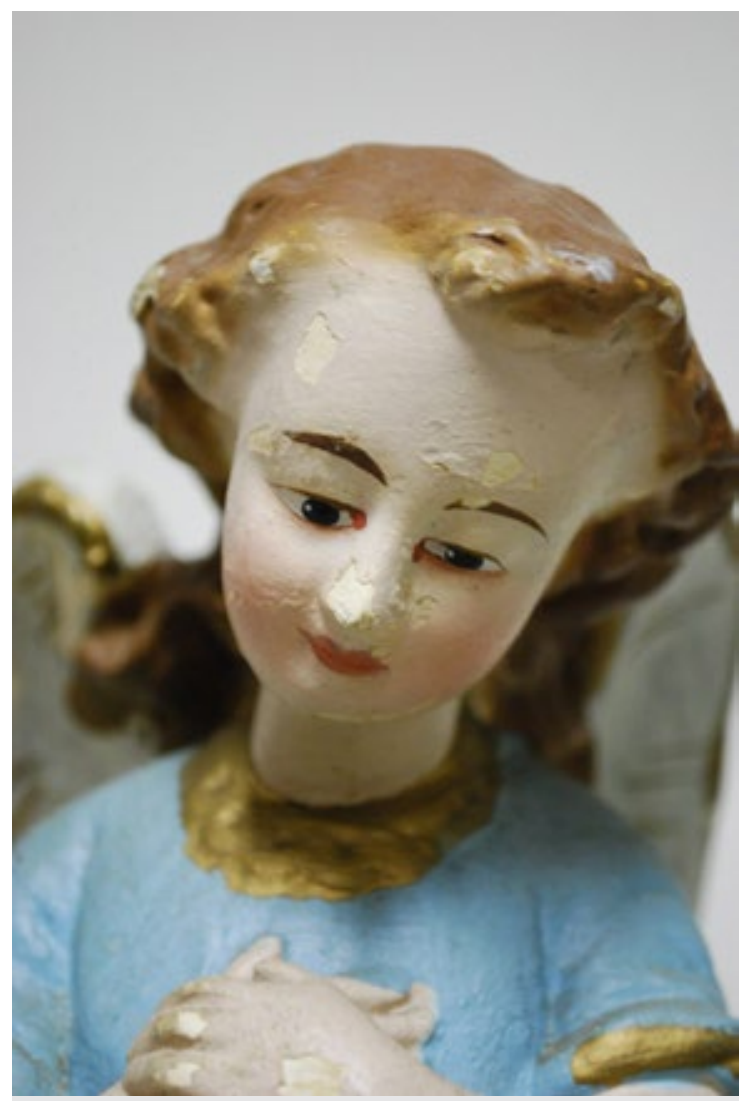

Fig. 13 Detail, face of angel from a pair of Adoring Angels

(see, for example, Fig. 12) and even "hospitalized" them for repairs.

Repair services were necessary, of course, because of the objects' susceptibility to easy breakage and chipping. In the first half of the twentieth century, ecclesiastical enterprises emerged to provide these services. The object's fragility, however, seemed to be part of the appeal (Fig. 13). In this regard they seemed almost human, evoking human frailties and mortality. This was especially the case for those figures used in last rites cabinets and sick call boxes. In the second half of the twentieth century, alternative media, plastic, fiberglass, resin, and various composite materials, offered greater durability. These have yet to completely replace chalkware however.

Third, these were objects that made physical demands upon recipients and practitioners in terms of bodily comportment, posture, and gesture. They were possessions as objects (commodities marketed through usual channels of commerce as well as church supply houses, with elaborate advertising apparatus, including pictorial catalogs) but they also aimed to "possess" practitioners in proximity to them with respect to gaze and gestural and postural demands. While these statues often replicated the full figure of the human body, they did not mirror what was already there but rather modeled what should be there. They insisted on imitation as the appropriate response and required that the believing beholder conform her/his body to mirror the statue's own stance or, alternatively and further, to render due submission and devotion. At least as an ideal, 
they modeled quiet, restrained, submissive postures of perpetual adoration, as assumed (for the moment at any rate) by the children who stood next to them in countless photos, striking clearly practiced and rehearsed poses.

Fourth, manufacturers made these objects in a range of sizes. Variations in scale multiplied and modified the possibilities for reception and especially the nature of the physical encounter. The material effects of tactility parsed here as well: smaller objects could be picked up and carried around, dressed and more immediately handled (see Fig. 2 for example). Larger, even life-scale, statues also invited intimate contact (touching, stroking, or kissing) but were not subject to the same degree of mobility in personal handling.

Fifth, practitioners ascribed a certain agency and/or liveliness to, or through, these objects. This was most obviously the case where Catholic figural statues were concerned and was apparent in numerous ways, including the deliberate siting of them so as to provide, for example, a beautiful vista for surveying and blessing vast spaces. Protestant examples abound as well. Here the figural objects were more likely (though not exclusively) plaster pictures in relief, representing an iconic narrative scene from the life of Jesus, for example. One domestic devotional chalk object, marketed to both Protestants and Catholics, took the shape of a head of Jesus whose eyes appeared to focus on the viewer wherever she or he stood in the room (Fig. 14).

Plaster plaques with scriptural and other inspirational verses often accompanied by decorative features drawn largely from nature dominated the Protestant market in chalkware (see for example Fig. 15). Common blackboard chalk, interestingly, is usually made from gypsum plaster. The "chalk talk" provided a generally Protestant variation on the use of this medium. Here a preacher or evangelist or teacher, in the church

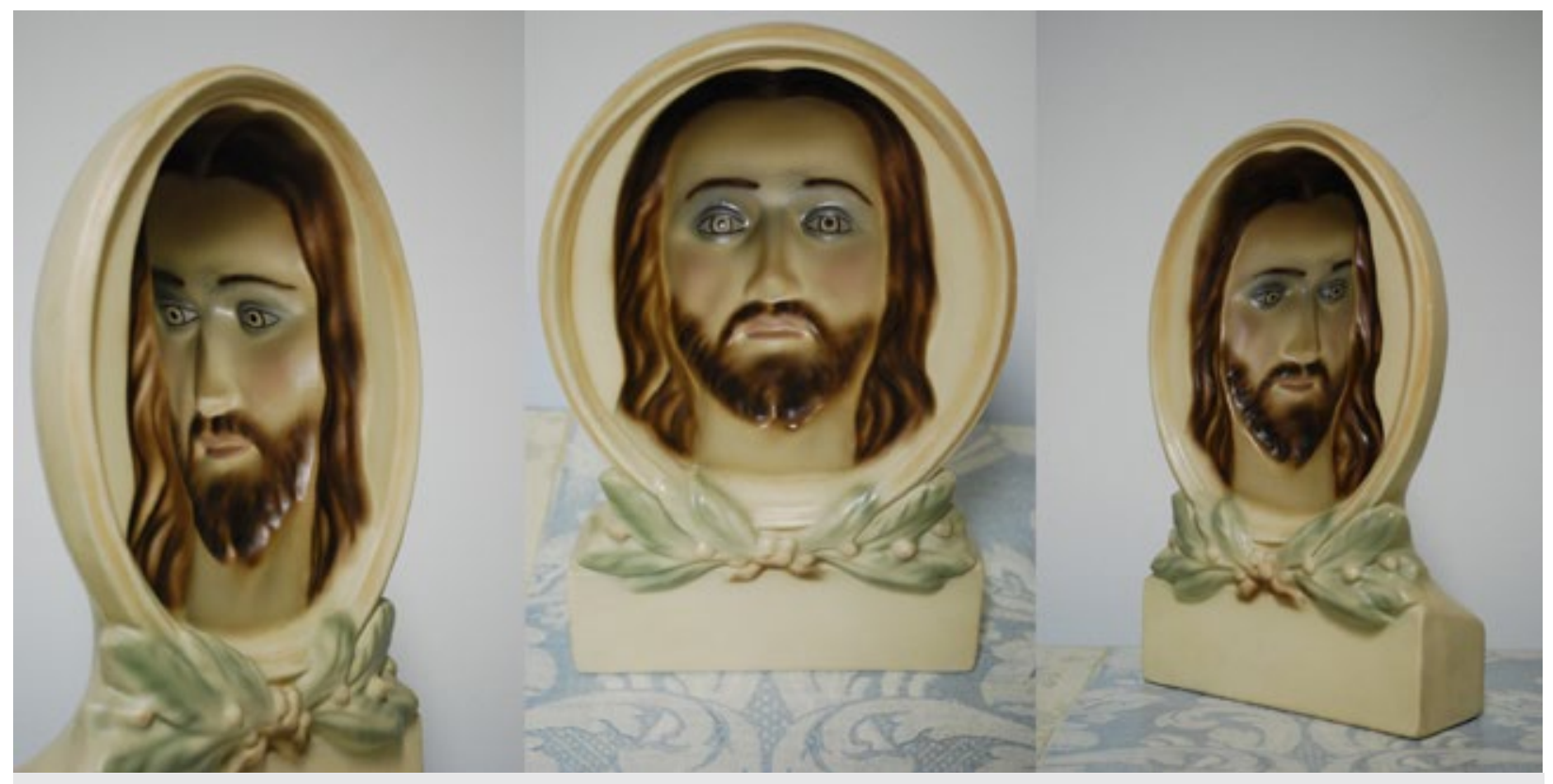

Fig. 14 Face of Jesus, mid 20th century 
sanctuary itself or in an educational space or auditorium, performed the process of drawing in chalk the face of Jesus or the contours of a scriptural story or a Christian symbol, all the while sharing a relevant sermon or "talk."

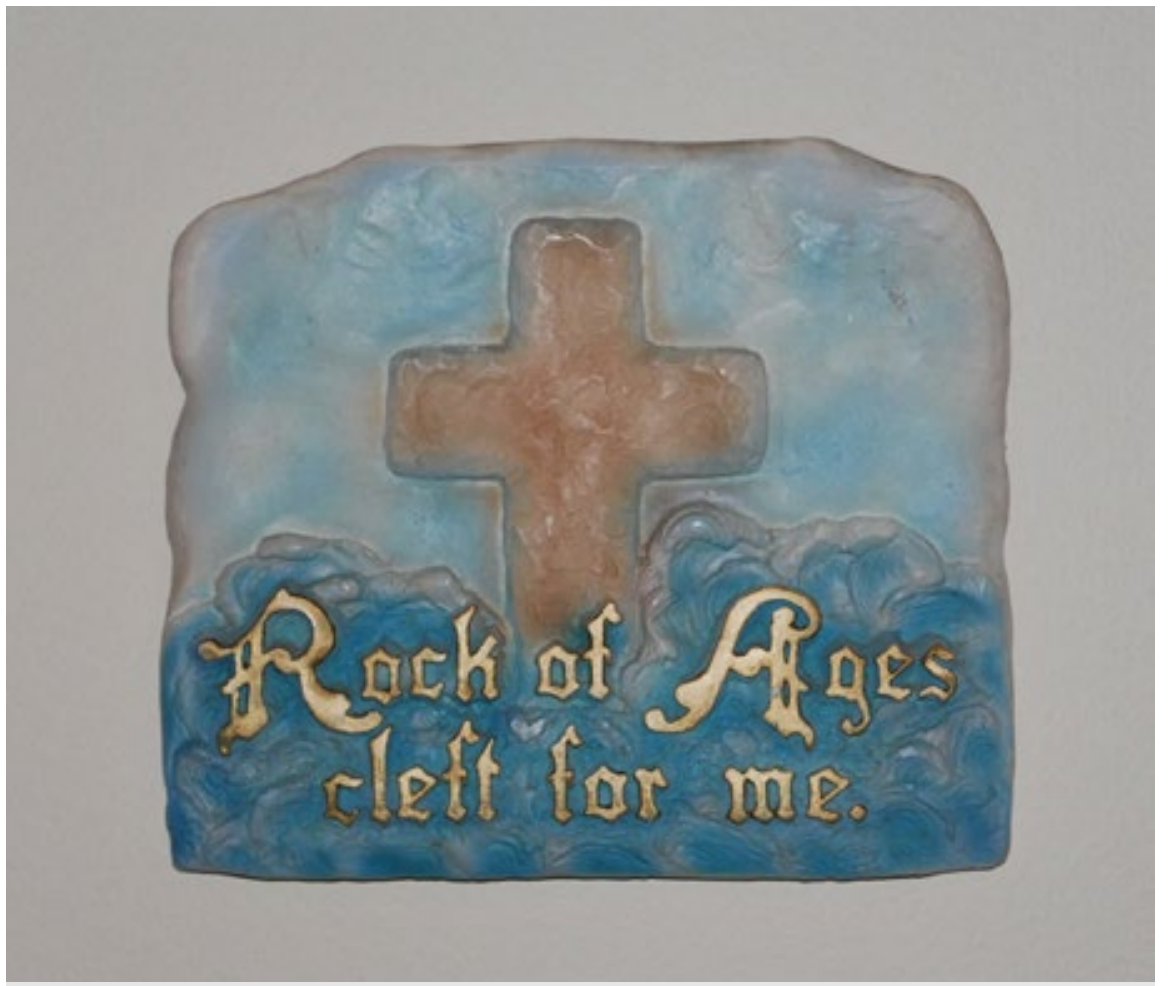

Fig. 15 Rock of Ages plaque, ca. 1958

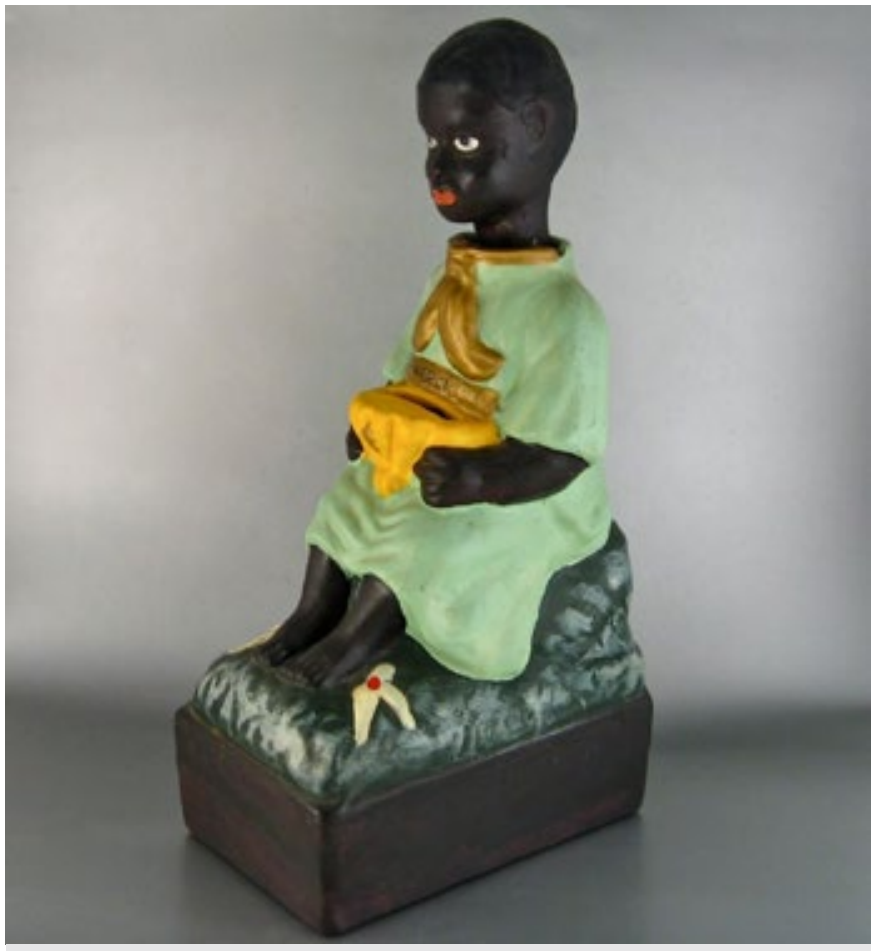

Fig. 16 Missions donation box, early 2oth century 
Sixth, and finally for this present essay, these figural objects functioned as white models of white piety and divinity, models that reinforced the authority of white agency in the missions field and colonial enterprise as well as at home (Fig. 17). In a Christian culture of conversion, that metaphorically and scripturally equated whiteness with purity and salvation, chalkware was not a neutral medium. In many instances "finished" statues were merely waxed or glazed, protectively coating the white surface but leaving it stark white. Dark-"skinned" examples in the missions field often assumed postures of gratitude for (white) favors granted (Fig. 16). Numerous cases from the late 1960 s and 1970 in which "vandals" painted black the exposed skin (faces and hands) of larger scale white objects suggest that the connections to race and racism were fairly widely recognized.

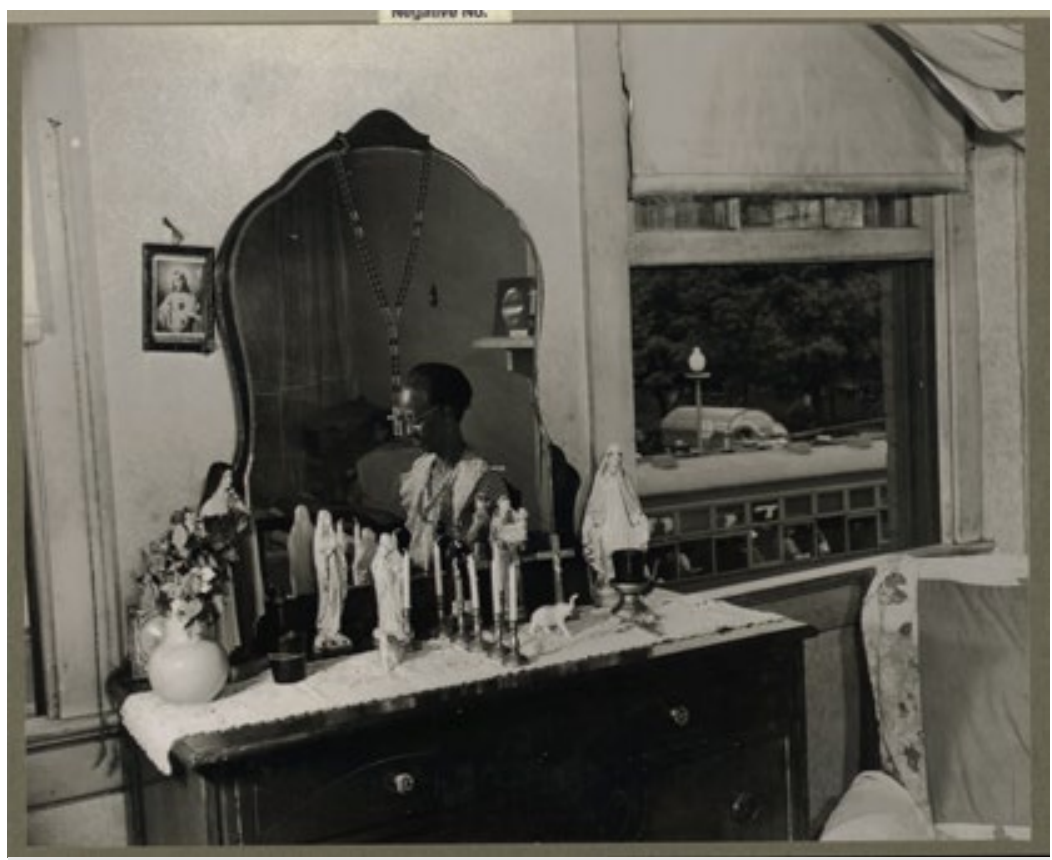

Fig. 17 Gordon Parks, photographer, Dresser in the bedroom of Mrs. Ella Watson, a government charwoman, August 1942

(C) Sally M. Promey

\section{Citation Guide}

1. Sally M. Promey, "Chalkware, Plaster, Plaster of Paris," Medium Study, in Conversations: An Online Journal of the Center for the Study of Material and Visual Cultures of Religion (2014), doi:10.22332/con.mst.2014.1

Promey, Sally M. "Chalkware, Plaster, Plaster of Paris." Medium Study. In Conversations: An Online Journal of the Center for the Study of Material and Visual Cultures of Religion (2014). doi:10.22332/con.mst.2014.1 


\section{Notes}

1. See Peter C. Marzio, The Democratic Art: Pictures for Nineteenth-Century America, Chromolithography, 1840-190o (D.R. Godine, 1979); and Michael Twyman, A History of Chromolithography: Printed Colour for All (British Library Publishing Department, 2013).

2. In March 2010 the Victoria and Albert Museum in London hosted a conference titled "Plaster and Plaster Casts: Materiality and Practice." Organized by Eckart Marchand, Marjorie Trusted, and Charles Hind, the gathering focused attention on a wide range of related subjects.

3. Tara Hamling's Decorating the "Godly" Household: Religious Art in PostReformation Britain (Yale University Press, 2010) explores the uses of large-scale religious figural and ornamental plaster moldings, mantels, wall panels, ceilings, and other interior architectural decoration in Protestant domestic spaces from 1560 to 1660.

\section{Yale}

Copyright 2016 Yale University All rights reserved. 